\title{
APLICAÇÃO DO TESTE DE TETRAZÓLIO EM SEMENTES DE Gleditschia amorphoides Taub. CAESALPINACEAE ${ }^{1}$
}

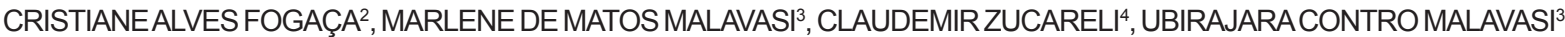

\begin{abstract}
RESUMO - Este trabalho teve como objetivos padronizar a metodologia do teste de tetrazólio e avaliar a aplicabilidade deste para estimar a viabilidade de sementes de Gleditschia amorphoides. Inicialmente, foram avaliados os seguintes tratamentos de pré-condicionamento: semente intacta, escarificação mecânica, escarificação seguida de 24 ou 48 horas de embebição em água, com e sem posterior retirada do tegumento. Em seguida, as sementes foram submetidas a 1, 3 ou 6 horas de coloração em solução de 2, 3, 5 trifenil cloreto de tetrazólio às concentrações de 0,$025 ; 0,050 ; 0,075$ ou $0,10 \%$ a $35^{\circ} \mathrm{C}$, no escuro. Sementes escarificadas e embebidas por 48 horas, com retirada do tegumento, imersas em solução de tetrazólio a $0,075 \%$ por 3 horas apresentaram coloração ideal, possibilitando a identificação das sementes em viáveis e inviáveis. Utilizando o protocolo acima descrito, avaliou-se a adequação do teste de tetrazólio em estimar a viabilidade de sementes de Gleditschia amorphoides através da comparação com o teste de germinação. A comparação não resultou em diferenças significativas entre eles. O teste de tetrazólio utilizando solução a 0,075\% por 3 horas pode ser utilizado na estimativa da viabilidade de sementes de Gleditschia amorphoides.
\end{abstract}

Termos para indexação: sementes florestais, viabilidade, sucará.

\section{APPLICATION OF THE TETRAZOLIUM TEST IN Gleditschia amorphoides Taub. SEEDS - CAESALPINACEAE}

\begin{abstract}
The objectives of the study were to standardize the tetrazolium test and to evaluate its applicability to estimate viability of Gleditschia amorphoides seeds. Initially, different preconditioning treatments were tested: intact seed, mechanical scarification, scarification followed by 24 or 48 hours of imbibition, with and without seed coat removal. All the pre-treated seeds were submitted to 1,3 or 6 hours in tetrazolium solution at $0.025 ; 0.050 ; 0.075$ and $0.10 \%$ at $35^{\circ} \mathrm{C}$, in the dark. Seeds subjected to scarification and imbibed for 48 hours, with seed coat removal immersed in $0.075 \%$ solution for 3 hours presented ideal coloration making possible the distinction of viable from unviable seeds. Using the above described protocol we evaluated it to estimate viability of Gleditschia amorphoides seeds by comparing with germination tests. There were no significant differences between results from either test. The protocol using $0.075 \%$ tetrazolium solution for 3 hours can estimate viability of Gleditschia amorphoides seeds.
\end{abstract}

Index terms: forest seeds, viability, sucará.

\section{INTRODUÇÃO}

Gleditschia amorphoides Taub. (sucará), pertence à família Caesalpinaceae sendo recomendada para reflorestamentos heterogêneos com fins preservacionistas.

\footnotetext{
${ }^{1}$ Submetido em 01/03/2005. Aceito para publicação em 08/06/2006;

${ }^{2}$ Pós-graduanda Engenharia Florestal, UFPR, CEP: 80210-170, Curitiba PR, fogacac@zipmail.com.br;
}

As sementes desta espécie quando escarificadas levam de quatro a cinco semanas para germinarem (Lorenzi, 1998). Fogaça et al. (1999) observaram que quando as sementes de sucará foram submetidas à escarificação mecânica, a emissão da raiz primária ocorreu sete dias após a semeadura. No

\footnotetext{
${ }^{3}$ Professor UNIOESTE - CCA, Marechal Cândido Rondon - PR. CEP: 85960-000,malavasi@unioeste.br;

${ }^{4}$ Pós-graduando em Agricultura, FCA/UNESP, Botucatu - SP, claudemir@fca.unesp.br.
} 
entanto, para a completa germinação são necessárias quatro semanas. $\mathrm{O}$ resultado do teste de germinação pode já não mais representar a real capacidade de germinação do lote, uma vez que alterações na qualidade da semente podem ocorrer dependendo das condições ambientais.

Considerando que a maioria das espécies florestais exige longo período para germinar, até um ano com sementes de Bertholletia excelsa (castanha-do-pará) ou seis meses com sementes de Joahnesia princeps (boleira), o desenvolvimento de testes rápidos e eficientes para a avaliação da viabilidade de sementes é necessário (Piña-Rodrigues e Santos, 1988).

Embora o teste de germinação seja o parâmetro oficial mais utilizado para avaliar a qualidade fisiológica de lotes de sementes, Vieira (1988), Arthur e Tonkin (1991), Krzyzanowski et al. (1991) e Piana et al. (1992) atribuíram sérias limitações àquele teste. Além da demora na execução, o teste de germinação não permite precisão na identificação dos fatores que afetam a qualidade das sementes e os resultados podem ser alterados pela presença de fungos. Assim, a avaliação da qualidade de sementes com testes rápidos que proporcionem resultados reproduzíveis tem sido alvo constante dos Tecnologistas de Sementes (Prete et al., 1993).

Entre os testes indiretos considerados rápidos, o teste de tetrazólio destaca-se, pois além de avaliar a viabilidade e o vigor, permite em alguns casos a identificação dos fatores que influenciam a qualidade das sementes como danos mecânicos e os causados pela secagem, por insetos e deterioração por umidade (Bhéring et al., 1996; França Neto, 1999).

O teste de tetrazólio fundamenta-se na alteração da coloração dos tecidos da semente em presença de uma solução de sal de tetrazólio, o qual é reduzido pelas enzimas desidrogenases dos tecidos vivos, resultando num composto denominado de formazam, de coloração vermelha-carmim. Tecidos mortos ou muito deteriorados apresentaram-se descoloridos. O padrão de coloração dos tecidos pode ser utilizado para identificar sementes viáveis, não viáveis e, dentro da categoria viável, as de alto e baixo vigor (Vieira e VonPinho, 1999). A coloração vermelha-brilhante ou rosa-brilhante se desenvolve quando o hidrogênio resultante do processo de respiração das células vivas combina-se com a solução de tetrazólio absorvida. Os tecidos do embrião viável absorvem a solução de tetrazólio lentamente e tendem a desenvolver uma coloração mais leve que os embriões deteriorados que adquirem uma cor vermelha-carmim forte. A presença de tecidos não coloridos, firmes e sadios sugere maior resistência à penetração da solução de tetrazólio do que a morte do tecido.
O tecido morto geralmente é caracterizado por cor branca ou amarelada e textura flácida (Bhéring et al., 1996; França Neto, 1999).

O teste de tetrazólio apresenta várias vantagens: não é afetado por diversas condições que podem alterar os resultados do teste padrão de germinação, como a presença de fungos; enfoca as condições físicas e fisiológicas do embrião de cada semente individualmente; permite rápida avaliação da viabilidade; permite em algumas espécies, como soja e feijão, a identificação de diferentes níveis de viabilidade; pode fornecer o diagnóstico da causa da perda da viabilidade das sementes e requer equipamento simples e barato (Delouche et al., 1976; França Neto et al., 1998; França Neto, 1999).

Conforme Piña-Rodrigues e Santos (1988), o teste de tetrazólio não é muito difundido entre espécies perenes, como florestais e frutíferas, embora apresente excelentes condições para ser utilizado rotineiramente, uma vez que muitas dessas espécies necessitam de longo período para germinarem. Em vista dessa situação, pesquisas têm sido desenvolvidas procurando abreviar o prazo requerido para obtenção dos resultados do teste de tetrazólio, a partir da definição de metodologia adequada e padronizada para cada espécie (Nascimento e Carvalho, 1998).

Assim, a metodologia para o teste de tetrazólio vem sendo estudada para diversas espécies florestais como canela preta (Silva et al., 1997); jenipapo (Nascimento e Carvalho, 1998); farinha seca (Zucareli et al., 1999); araucária (Sorol e Pérez, 2001); canafístula (Oliveira et al., 2001a); copaíba (Fogaça et al., 2001); guapuruvu (Paula et al., 2001); ipê-amarelo (Oliveira et al., 2001b); louro pardo (Mendonça et al., 2001) e pata-de-vaca (Krohn et al., 2001).

Diante do exposto, o presente trabalho teve por objetivos padronizar a metodologia do teste de tetrazólio e avaliar a aplicabilidade deste para a estimativa da viabilidade de sementes de Gleditschia amorphoides Taub.

\section{MATERIALE MÉTODOS}

Este trabalho foi conduzido no Laboratório de Tecnologia de Sementes da Universidade Estadual do Oeste do Paraná, Marechal Cândido Rondon, em duas fases. Na primeira, foram utilizadas sementes de Gleditschia amorphoides recémcoletadas na Área de Relevante Interesse Ecológico (ARIE), município de Santa Helena - PR, testando-se diferentes tratamentos de pré-condicionamento das sementes, concentrações da solução de tetrazólio e períodos de 
embebição à solução de tetrazólio.

Antes do período de reação na solução de tetrazólio, as sementes foram submetidas aos seguintes pré-tratamentos: controle, sementes escarificadas manualmente (com lixa $\mathrm{n}^{\circ}$ 80 na região oposta ao embrião), e sementes escarificadas manualmente e submetidas a 24 ou 48 horas de embebição, entre papel-toalha umedecido com água a $25^{\circ} \mathrm{C}$, com e sem posterior retirada do tegumento. A retirada do tegumento foi executada manualmente evitando-se danos ao embrião.

Após as preparações acima descritas, as sementes foram submersas por 1, 3 ou 6 horas em solução de 2,3,5 trifenil cloreto de tetrazólio ( $\mathrm{pH}$ 6,5 a 7,0) nas concentrações de 0,$025 ; 0,050 ; 0,075$ ou $0,10 \%$, em câmara regulada a $35^{\circ} \mathrm{C}$, no escuro. Utilizaram-se quatro repetições de 25 sementes para cada combinação de preparação da semente, concentração da solução de tetrazólio, e período de coloração. As sementes foram acondicionadas em recipientes plásticos de $200 \mathrm{~mL}$ com solução de tetrazólio em quantidade suficiente para cobri-las. Ao término de cada período de coloração, a solução foi drenada, as sementes lavadas em água corrente e mantidas submersas em água em ambiente refrigerado até o momento da avaliação.

As sementes foram avaliadas uma a uma, seccionandoas longitudinalmente através do centro do eixo embrionário com auxílio de bisturi. A visualização de todos os detalhes das sementes contou com o auxílio de um microscópio estereoscópico de quatro aumentos (4x). Para a caracterização das classes de coloração, elaborou-se uma representação de oito diagramas de coloração das sementes, observando-se a presença e a localização de danos, além das condições físicas das estruturas embrionárias. A escolha do procedimento de preparação e das condições mais adequadas considerou o aspecto dos tecidos, a intensidade e a uniformidade da coloração.

$\mathrm{Na}$ segunda fase deste estudo, a eficácia do teste de tetrazólio na estimativa da viabilidade de sementes de sucará foi avaliada através da comparação dos resultados dos testes de tetrazólio e germinação. Para a comparação foram utilizados três lotes de sementes coletados no local anteriormente descrito. O LOTE 1 foi armazenado por dois anos, sendo o primeiro ano em câmara fria a $15^{\circ} \mathrm{C}$ e o segundo ano em câmara com temperatura entre $18-20^{\circ} \mathrm{C}$ e $40 \%$ de umidade relativa do ar (UR), em saco plástico. O LOTE 2 foi armazenado por um ano, embalado em saco plástico, e mantido em câmara com temperatura entre $18-20^{\circ} \mathrm{C}$ e $40 \%$ de UR. O LOTE 3 foi coletado e utilizado imediatamente.

De acordo com as recomendações de Delouche et al.
(1976), os lotes utilizados foram divididos em duas amostras; uma utilizada para o teste de germinação e a outra para o teste de tetrazólio. O grau de umidade foi determinado de acordo com as Regras para Análise de Sementes (Brasil, 1992).

O teste de germinação foi realizado com quatro repetições de 25 sementes, em rolos de papel, em câmara de germinação à temperatura constante de $25^{\circ} \mathrm{C}$ e fotoperíodo de 12 horas. As avaliações foram realizadas diariamente, a partir do momento em que as plântulas apresentaram todas as suas estruturas desenvolvidas. Os resultados foram expressos em porcentagem de plântulas normais.

Pelo fato do teste de tetrazólio não diferenciar sementes dormentes daquelas não-dormentes (Grabe, 1976), evitou-se discrepâncias entre os resultados dos testes de tetrazólio e de germinação submetendo as sementes de sucará ao tratamento indicado para superação da dormência (Fogaça et al., 1999) antes da realização dos testes.

Para o teste de tetrazólio foram utilizadas quatro repetições de 25 sementes escarificadas com lixa $n^{\circ} 80$, submetidas a 48 horas de embebição entre papel toalha a $25^{\circ} \mathrm{C}$, com posterior retirada manual do tegumento. As sementes foram então submersas em solução de tetrazólio a $0,075 \%$ por 3 horas. Durante o período de coloração as amostras foram mantidas a $35^{\circ} \mathrm{C}$, no escuro. Após este período, as sementes foram avaliadas individualmente, seccionando-as longitudinalmente através do centro do eixo embrionário com auxílio de bisturi. As estruturas e sua coloração foram observadas com auxílio de microscópio estereoscópico de quatro aumentos $(4 x)$. Para a caracterização dos níveis de viabilidade foi elaborada uma representação de sementes viáveis e inviáveis, observando a presença e a localização do dano, além das condições físicas das estruturas embrionárias. A diferenciação de cores dos tecidos foi observada de acordo com os critérios estabelecidos para o teste de tetrazólio (Delouche et al, 1976; Bhéring et al., 1996; França Neto, 1999): vermelho brilhante ou rosa (tecido vivo e vigoroso), vermelhocarmim forte (tecido em deterioração) e branco leitoso ou amarelado (tecido morto).

O delineamento experimental foi inteiramente casualizado. Os resultados obtidos nos testes de germinação e tetrazólio, para cada lote, foram submetidos à análise de variância e as médias comparadas através do teste de Tukey a 5\% de probabilidade.

\section{RESULTADOS E DISCUSSÃO}

Independentemente das concentrações da solução de 
tetrazólio e do tempo de reação estabelecido, não houve desenvolvimento de coloração nas sementes intactas (controle). Este fato pode ser atribuído ao tegumento impermeável desta espécie que impediu a penetração da solução de tetrazólio. De acordo com Grabe (1976), tegumentos espessos e duros devem ser removidos antes da coloração, como é o caso das sementes de algodão.

Nas preparações com escarificação mecânica e escarificação seguida de embebição por 24 horas sem retirada do tegumento, as sementes apresentaram coloração original, com exceção da região escarificada que se apresentou levemente colorida. Esta ausência de coloração pode ser atribuída a dois aspectos: presença do tegumento ou formação de substância gelatinosa na região escarificada, impedindo ou dificultando a penetração uniforme da solução do tetrazólio para o interior da semente. A remoção do tegumento das sementes, antes da imersão em solução de tetrazólio, embora seja uma operação delicada e trabalhosa, possibilita reduzir o tempo necessário para que estas adquiram a coloração adequada (Bittencourt e Vieira, 1999).

A preparação envolvendo escarificação mecânica, seguida de embebição em água por 24 horas e retirada manual do tegumento apresentou coloração desuniforme. Muitas sementes não apresentaram coloração na região central do tecido de reserva e no eixo embrionário, colorindo apenas nas extremidades das sementes, devido aos danos causados pela retirada do tegumento, não permitindo a correta avaliação. Os problemas com as observações do presente estudo são similares àquelas de Delouche et al. (1976) com sementes de rabanete escarificadas, submetidas à embebição em água por uma noite, seguido da retirada do tegumento e submersas em solução de tetrazólio $1,0 \%$ por 1 a 2 horas a $40^{\circ} \mathrm{C}$.

As sementes que durante a preparação foram submetidas à escarificação mecânica seguidas de embebição por 48 horas, sem retirada do tegumento, apresentaram coloração intensa na região escarificada, com manchas rosadas dispersas no tecido de reserva, sem contudo atingir o eixo embrionário. Considerando que o embrião, localizado na parte interna da semente, é a principal estrutura a ser analisada na determinação da viabilidade e do vigor, a coloração da parte interna da semente é fundamental.

As sementes escarificadas e embebidas em água por 48 horas, com retirada do tegumento, quando submersas em tetrazólio a 0,050 ou $0,075 \%$ por 3 horas ou 6 horas ou em solução a $0,10 \%$ por uma hora apresentaram coloração ideal, permitindo a diferenciação e avaliação das condições em que se encontravam os tecidos das sementes. Quando se utilizou a concentração de $0,10 \%$ por períodos superiores a uma hora houve desenvolvimento de coloração intensa, impossibilitando a avaliação das condições dos tecidos das sementes.

O preparo das sementes, a concentração da solução de tetrazólio e o tempo de coloração são específicos para cada espécie. Utilizando sementes de guapuruvu, Paula et al. (2001) obtiveram distinta coloração dos tecidos vivos com sementes embebidas por 48 horas a $35^{\circ} \mathrm{C}$, com posterior retirada do tegumento, utilizando solução de tetrazólio a $0,10 \%$ por 4 horas ou $0,20 \%$ por 3 horas, acondicionadas em câmara a $35^{\circ} \mathrm{C}$, no escuro. Krohn et al. (2001) reportaram resultados consistentes do teste de tetrazólio em sementes de pata-devaca com embebição por 16 horas a $35^{\circ} \mathrm{C}$ e posterior retirada do tegumento, submetidas à solução $0,050 \%$ por 3 ou 4 horas, em câmara a $35^{\circ} \mathrm{C}$.

$\mathrm{Na}$ Figura 1 está representada, em diagrama, a classificação dos níveis de viabilidade estabelecidos no teste de tetrazólio para sementes de Gleditschia amorphoides considerando as seguintes características como critério para a classificação das sementes: 1. tecidos com coloração vermelha brilhante uniforme ou rósea são típicos de tecido sadio; 2. tecidos com coloração branca ou amarelada são tecidos mortos; 3. tecidos com coloração vermelha intensa são tecidos em deterioração. A descrição das classes de viabilidade é a seguinte:

Classe 1 - Viável: semente com coloração rósea uniforme e todos os tecidos com aspecto normal e firme;

Classe 2 - Viável: semente apresentando menos de 50\% dos cotilédones com coloração vermelha intensa, típico de tecido em deterioração;

Classe 3 - Viável: extremidade da radícula com coloração branca leitosa sem atingir o cilindro central, além de apresentar manchas branca leitosa e vermelha intensa dispersas;

Classe 4 - Viável: semente apresentando menos de 50\% da região cotiledonar com coloração branca leitosa, caracterizando tecido morto;

Classe 5 - Inviável: eixo embrionário e mais de $50 \%$ da região cotiledonar apresentando coloração vermelha intensa típica de tecidos em deterioração;

Classe 6 - Inviável: semente totalmente com coloração vermelha intensa, indicando processo acentuado de deterioração;

Classe 7 - Inviável: eixo embrionário com coloração branca leitosa, apresentando o cilindro central com coloração vermelha intensa. Região cotiledonar apresentando mais de $50 \%$ com coloração branca leitosa, com manchas vermelhas intensas dispersas; 

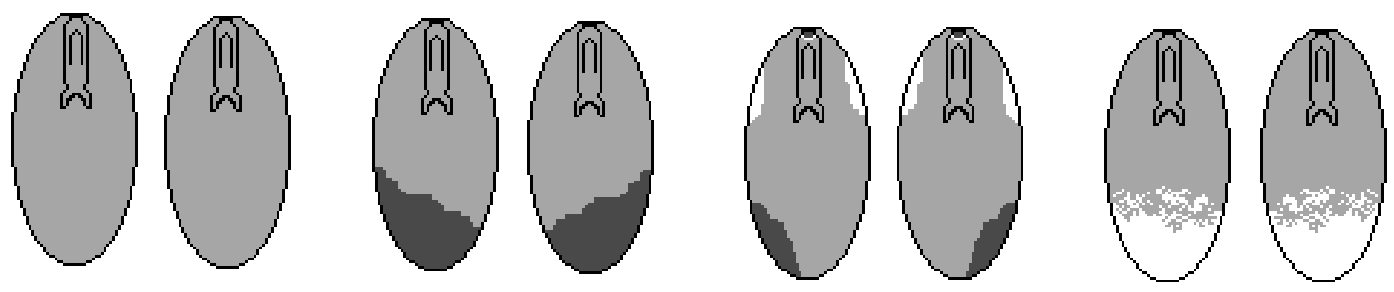

Classe 1

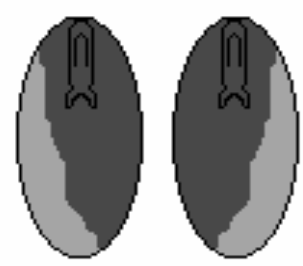

Classe 5
Classe 2

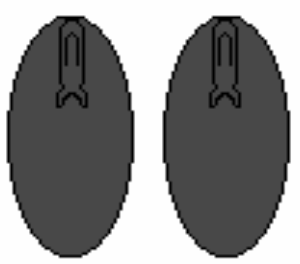

Classe 6
Classe 3

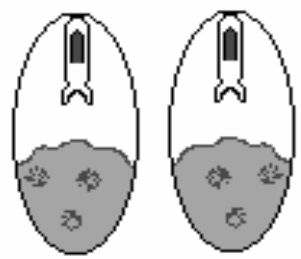

Classe 7

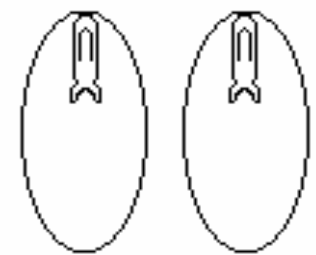

Classe 8

Legenda: $\square$ Vermelho intenso

Róseo

Branco leitoso

FIGURA 1. Representação diagramática das classes de sementes estabelecidas no teste de tetrazólio para a espécie florestal Gleditschia amorphoides.

Classe 8 - Inviável: semente totalmente branca leitosa apresentando tecidos flácidos.

Não foi observada diferença estatisticamente significativa entre as amostras retiradas dos três lotes de sementes de Gleditschia amorphoides em relação ao grau de umidade cuja média foi de $8 \%$.

Conforme os resultados expressos na Tabela 1, observou-se que a metodologia empregada para o teste de tetrazólio não proporcionaram estimativas de viabilidade das sementes de Gleditschia amorphoides diferentes dos resultados obtidos no teste de germinação. Amaral e Alcalay (1997) indicaram que o teste de tetrazólio é uma alternativa rápida e precisa para a avaliação da qualidade fisiológica de sementes das espécies florestais Aleurites fordii (tungue), Cedrela fissilis (cedro), Jacaranda micrantha (caroba), Leuhea divaricata (açoita-cavalo), e Hovenia dulcis (uva-do-Japão).

$\mathrm{O}$ teste de tetrazólio por se tratar de um teste rápido e confiável na análise de sementes, fornecendo informações mais rapidamente que o teste de germinação, é recomendado para avaliação de várias espécies florestais, tais como, Kielmeyera coriacea - pau-de-santo (Davide et al., 1997), Magonia pubescens - tingui (Malavasi et al., 1997), Albizia hasslerii - farinha seca (Malavasi et al., 1999), Tapirira guianensis - gurucaia (Ramos et al., 1999), Aspidosperma subincanum - peroba-de-gomo, Aspidosperma discolor guatambu vermelho e Tabebuia alba - ipê-amarelo (Matteucci et al., 1997).

Conforme discutidas e justificadas, as condições empregadas para a avaliação da eficiência do teste de tetrazólio foram definidas levando em consideração à facilidade de

TABELA 1. Resultados do teste de germinação e do teste de tetrazólio para avaliação da viabilidade de sementes de Gleditschia amorphoides.

\begin{tabular}{cccc}
\hline Lotes & Amostras & Germinação $\%$ & Tetrazólio \% \\
\hline \multirow{2}{*}{1} & 1 & $91 \mathrm{Aa}^{(1)}$ & $86 \mathrm{Aa}$ \\
& 2 & $89 \mathrm{Aa}$ & $87 \mathrm{Aa}$ \\
2 & 1 & $87 \mathrm{Aa}$ & $91 \mathrm{Aa}$ \\
& 2 & $90 \mathrm{Aa}$ & $91 \mathrm{Aa}$ \\
3 & 1 & $96 \mathrm{Aa}$ & $98 \mathrm{Aa}$ \\
& 2 & $95 \mathrm{Aa}$ & $98 \mathrm{Aa}$ \\
\hline
\end{tabular}

(1) Médias seguidas das mesmas letras maiúsculas na coluna e minúsculas na linha, não diferem estatisticamente pelo Teste de Tukey, a 5\% de probabilidade. 
exposição dos tecidos, à economicidade, à rapidez para a obtenção dos resultados e à comparação com o teste de germinação. A interpretação dos resultados obtidos neste trabalho permite inferir que o teste de tetrazólio pode ser utilizado na determinação da viabilidade das sementes de Gleditschia amorphoides.

\section{CONCLUSÃO}

O procedimento com sementes escarificadas mecanicamente, embebidas em água por 48 horas, com posterior retirada do tegumento e expostas à solução de tetrazólio $0,075 \%$ por 3 horas a $35^{\circ} \mathrm{C}$ no escuro é adequado para avaliação da viabilidade de sementes de Gleditschia amorphoides.

\section{REFERÊNCIAS}

AMARAL, D.M.I.; ALCALAY, N. Emprego do teste de tetrazólio em cinco espécies florestais do Rio Grande do Sul. Informativo ABRATES, Curitiba, v.7, n.1/2, p.221, 1997.

ARTHUR, T.J.; TONKIN, J.H.B. Testando o vigor de sementes. Informativo ABRATES, Londrina, v.1, n.3, p.38-41, 1991.

BHÉRING, M.C.; SILVA, R.F.; ALVARENGA, E.M.; DIAS, D.N.F.S.; PENA, M.F. Avaliação da viabilidade e do vigor de sementes de feijão de vagem (Phaseolus vulgaris L.) pelo teste de tetrazólio. Boletim Técnico UFV.Viçosa, 1996. 27p.

BITTENCOURT, S.R.M.; VIEIRA, R.D. Metodologia do teste de tetrazólio em sementes de amendoim. In: KRZYZANOWSKI, F.C.; VIEIRA, R.D. ; FRANÇA NETO, J.B.(Ed.). Vigor de sementes: conceitos e testes. Londrina: ABRATES, 1999. 218p.

BRASIL. Ministério da Agricultura e da Reforma Agrária. Regras para Análise de Sementes. Brasília: SNDA/DNDV/CLAV, 1992. $365 p$.

DAVIDE, A.C.; MALAVASI, M.M.; OLIVEIRA, L.M.; MACHADO, C.F.; TONETTI, O.A.O. Uso do teste de tetrazólio para avaliar a qualidade de sementes de pau-santo (Kielmeyera coriacea (Pr.) Mart.) - Guttiferae. Informativo ABRATES, Curitiba, v.7, n.1/2, p.219, 1997.

DELOUCHE, J.C.; STILL, T.W.; RASPET, M.; LIENHARD, M. O teste de tetrazólio para viabilidade da semente. Brasília: AGIPLAN, 1976. $103 \mathrm{p}$

FOGAÇA, C.A.; MALAVASI, M.M.; ZUCARELI, C. Comparação entre diferentes tratamentos para superar a dormência de sementes de sucará (Gleditschia amorphoides Taub.) - FabaceaeCaesalpinoideae. Informativo ABRATES, Curitiba, v.9, n.1/2, p.172, 1999

FOGAÇA, C.A.; KROHN, N.G.; SOUZA, M.A.; PAULA, R.C. Desenvolvimento do teste de tetrazólio para avaliação da viabilidade de sementes de Copaifera langsdorffii Desf. Caesalpinaceae. Informativo ABRATES, Curitiba, v.11, n.2, p.279, 2001 .
FRANÇA NETO, J.B.; KRYZANOWSKI, F.C.; COSTA, N.P. O teste de tetrazólio em sementes de soja. londrina: embrapa/ cnpso, 1998. 72p.

FRANÇA NETO, J.B. Teste de tetrazólio para determinação do vigor de sementes. In: KRZYZANOWSKI, F.C.; VIEIRA, R.D.; FRANÇA NETO, J.B. (Ed.).Vigor de sementes: conceitos e testes. Londrina: ABRATES, 1999. 218p.

GRABE, D. F. Manual do teste de tetrazólio em sementes. Brasília: AGIPLAN, 1976. 85p.

KROHN, N.G.; FOGAÇA, C.A.; SOUZA, M.A.; PAULA, R.C. Preparação e coloração de sementes de Bauhinia forficata Link. (Caesalpinaceae) para avaliação da viabilidade através do teste de tetrazólio. Informativo ABRATES, Curitiba, v.11, n.2, p.278, 2001.

KRZYZANOWSKI, F.C.; FRANÇA NETO, J.B.; HENNING, A.A. Relato dos testes de vigor disponíveis para as grandes culturas. Informativo ABRATES, Londrina, v.1, n.2, p.15-50, 1991.

LORENZI, H. Árvores brasileiras: manual de identificação e cultivo de plantas arbóreas nativas do Brasil, v.2. Nova Odessa: Plantarum, 1998. p.73.

MALAVASI, M.M.; DAVIDE, A.C.; OLIVEIRA, L.M.; MACHADO, C.F.; TONETTI, O.A.O. Avaliação da qualidade fisiológica de sementes de tingui (Magonia pubescens St. Hil. Sapindaceae) através do teste de tetrazólio. Informativo ABRATES, Curitiba, v.7, n.1/2, p.217, 1997.

MALAVASI, M.M.; ZUCARELI, C.; FOGAÇA, C.A. Avaliação da eficiência do teste de tetrazólio na determinação da viabilidade de sementes de farinha seca (Albizia hasslerii (Chodat) Burr. Fabaceae-Mimosoideae. Informativo ABRATES, Curitiba, v.9, n.1/ 2, p.165, 1999.

MATTEUCCI, M.B.A.; GUIMARÃES, N.N.R.; TIVERON FILHO, D. Utilização do teste de tetrazólio em sementes de Pimenta-demacaco (Xylopia aromatica (Lam.) Mart.) - Annonaceae. Informativo ABRATES, Curitiba, v.7, n.1/2, p.117, 1997.

MENDONÇA, E.A.F.; RAMOS, N.P.; PAULA, R.C. Viabilidade de sementes de louro pardo (Cordia trichotoma (Vellozo) Arrabida ex Steudel) através do teste de tetrazólio. Informativo ABRATES, Curitiba, v.11, n.2, p.113, 2001.

NASCIMENTO, W.M.O.; CARVALHO, N.M. Determinação da viabilidade de sementes de jenipapo (Genipa americana L.) através do teste de tetrazólio. Revista Brasileira de Sementes, Campinas, v.20, n.2, p.470-474, 1998.

OLIVEIRA, L.M.; CARVALHO, M.L.M.; DAVIDE, A.C. Utilização do teste de tetrazólio para avaliação da qualidade fisiológica de sementes de canafístula (Peltophorum dubium (Sprengel) Tauber - Caesalpinoideae). Informativo ABRATES, Curitiba, v.11, n.2, p.118, 2001a.

OLIVEIRA, L.M.; CARVALHO, M.L.M.; VON PINHO, E.V.R.; GUIMARÃES, R.M.; VIEIRA, M.G.G.C. Avaliação de metodologias para o pré-condicionamento e tempo de incubação de sementes de ipê-amarelo (Tabebuia serratifolia) submetidas ao teste de tetrazólio. Informativo ABRATES, Curitiba, v.11, n.2, p.257, 2001b.

PAULA, R.C.; SOUZA, M.A.; KROHN, N.G.; FOGAÇA, C.A. Padronização do teste de tetrazólio para avaliação da qualidade fisiológica de sementes de Schizolobium parahyba (Vell) Blake - 
Caesalpinaceae. Informativo ABRATES, Curitiba, v.11, n.2, p.278, 2001.

PIANA, Z.; TILLMANN, A.A.; SILVA, W.R. Avaliação da qualidade fisiológica de sementes através de testes rápidos. Informativo ABRATES, Londrina, v.3, n.1, p.37-46, 1992.

PIÑA-RODRIGUES, F.C.M.; SANTOS, N.R.F. Teste de tetrazólio. In: PIÑA-RODRIGUES, F.C.M.(coord.). Manual de análise de sementes florestais. Campinas: Fundação Cargill, 1988. p.91-100.

PRETE, C.E.C.; CICERO, S.M.; FOLEGATTI, P.R. Emergência de plântulas de soja no campo e sua relação com a embebição e condutividade elétrica das sementes. Semina, Londrina, v.15, n.1, p.32-37. 1993.

RAMOS, K.M.O.; BUENO, P.C.; SALOMÃO, A.N. Determinação da temperatura de germinação e do comportamento para fins de conservação de sementes de Tapirira guianensis Aubl. Anacardiaceae. Informativo ABRATES, Curitiba, v.9, n.1/2, p.73, 1999.

SILVA, S.C.; SANTOS, D.S.B.; SANTOS FILHO, B.G. Avaliação da qualidade física e fisiológica de sementes de barbatimão
(Styphnode4ndron adstringens (Mart.) Coville - Fabaceae Mimosoideae), submetidas ao armazenamento. Informativo ABRATES, Curitiba, v.7, n.1/2, p.207, 1997.

SOROL, C.B.; PÉREZ, M.A. Determinacion de la viabilidad de las semillas de araucaria (Araucaria angustifolia Bert. O. Ktze.) através de la prueba topográfica por tetrazolio. Informativo ABRATES, Curitiba, v.11, n.2, p.287, 2001.

VIEIRA, M.G.G.C. Aspectos de integração, tecnologia e sanidade em estudos de sementes. In: III SIMPÓSIO BRASILEIRO DE PATOLOGIA DE SEMENTES, 1988, Campinas. Anais... Campinas: Fundação Cargill, 1988. p.45-57.

VIEIRA, M.G.G.C.; VON PINHO, E.V.R. Metodologia do teste de tetrazólio em sementes de algodão. In: KRZYZANOWSKI, F.C.; VIEIRA, R.D.; FRANÇA NETO, J.B. (Ed.). Vigor de sementes: conceitos e testes. Londrina: ABRATES, 1999. p.8.1.1-8.1.13.

ZUCARELI, C.; MALAVASI, M.M.; FOGAÇA, C.A. Preparação e coloração de sementes de farinha seca (Albizia hasslerii (Chodat) Burr. - Fabaceae-Mimosoideae) para avaliação da viabilidade através do teste de tetazólio. Informativo ABRATES, Curitiba, v.9, n.1/2, p.166, 1999. 